\title{
Development and Validation of a Dissolution Method for Pioglitazone Tablets
}

\author{
A. P. Kulkarni ${ }^{*}$, Mohd Shahnawaz, \\ Zahid Zaheer, and M. H. G. Dehghan \\ Department of Quality Assurance, Dr. Maulana Azad Educational Trust's, Y. B. Chavan \\ College of Pharmacy, Rauza Bagh, Aurangabad-431001, Maharashtra, India
}

\begin{abstract}
Dissolution testing has emerged in the pharmaceutical field as a very important tool to characterize drug product performance. Pioglitazone hydrochloride, a frequently prescribed antidiabetic, has no dissolution assay in official monographs. The aim of the study was to develop and validate a dissolution test for the quality control of pioglitazone hydrochloride (PH) tablets containing $15 \mathrm{mg}$ of active pharmaceutical ingredient (API). Results from testing sink conditions and stability at $37^{\circ} \mathrm{C}$ show that $\mathrm{PH}$ is stable in potassium chloride buffer at $\mathrm{pH} 1.2,1.5,1.8$, and in $0.1 \mathrm{~N}$ hydrochloric acid. In vitro dissolution tests of $\mathrm{PH}$ tablets were performed using different test conditions but always under sink conditions. The effects of filtration and deaeration were evaluated. The most discriminatory test conditions, potassium chloride buffer at pH $1.5\left(900 \mathrm{~mL}\right.$ at $\left.37 \pm 0.5^{\circ} \mathrm{C}\right)$ as dissolution medium, paddle method (Apparatus 2), $75 \mathrm{rpm}$, and $60 \mathrm{~min}$, were satisfactory. The UV spectrophotometric method for determination of released PH was developed and validated. The method presented linearity $\left(r^{2}=0.999\right)$ in the concentration range of $10-60 \mu \mathrm{g} / \mathrm{mL}$. The recoveries were good, ranging from $96.407 \%$ to $100.24 \%$. The intraday and interday precision results were $1.704 \%$ and $1.3869 \%$ RSD, respectively. The developed dissolution test is adequate for its purpose and can be applied for the quality control of 15-mg PH tablets.
\end{abstract}

\section{INTRODUCTION}

$\mathrm{n}$ recent years, more emphasis has been placed on dissolution testing by the pharmaceutical industry and regulatory authorities. Dissolution tests are used to assess lot-to-lot quality of a drug product in the development of new formulations and in the assurance of product quality and performance after certain changes, such as in the formulation and the manufacturing process. From a biopharmaceutics point of view, a more discriminating dissolution method is preferred because the test will indicate possible changes in the quality of the product before in vivo performance is affected (1).

For drugs belonging to BCS Class 2, dissolution is the limiting step for drug absorption, and the dissolution profile must be quite definite and highly reproducible (2). The development of a meaningful dissolution procedure for drug products with limited water solubility has been a challenge to both the pharmaceutical industry and the regulatory agencies (3), since establishment of an in vitroin vivo correlation and the resulting ability to discriminate between formulations with different bioavailability is dependent on the design of in vitro dissolution tests (4). The dissolution test, a quality control test, may be used as a tool for predicting bioequivalence (3).

None of the purposes of dissolution test is fulfilled without performing validation of the dissolution test ensuring that a system is experimentally sound, yielding precise, accurate, and repeatable results. A recent interna-

\footnotetext{
*Corresponding author.
}

tional collaborative study indicated that drug dissolution testing is a highly variable technique. Consequently, in many cases the impact of formulation or manufacturing changes on drug release properties may not be detected, or conversely, differences caused by test variability rather than true differences could be recorded. Thus, careful control of experimental conditions is necessary to reduce test-to-test variability and improve test reproducibility and reliability (5).

The validation of the dissolution test can be divided into two parts. The first considers equipment validation; equipment has to be calibrated taking into consideration the specifications for geometry and alignment of the dissolution apparatus. The second concerns test validation and requires the study of the performance parameters, especially precision. The evaluation of precision is very important to assess the reliability of the data obtained by the dissolution test. In fact, it is true that a more discriminating dissolution method is preferred, but it is also true that a reliable dissolution test is of utmost importance. A dissolution test with good precision makes it possible to efficiently compare several alternative formulation candidates to select the dosage form with the most suitable and reproducible drug release profile (5).

Guidances on validation characteristics and considerations have been published, Validation of a dissolution method typically involves validation of the end analysis method for specificity, precision, linearity, accuracy, and range. There are three categories of precision: repeatability, reproducibility, and intermediate precision. Repeat- 
ability is the precision of the method under the same operating conditions over a short time. Reproducibility determines the precision between laboratories. Intermediate precision is a measure of intralaboratory variance using different operators on different days, equipment, and so forth, and is not required in cases where reproducibility has been performed. Method robustness should be evaluated, and if measurements are affected by variation in method parameters, then these should be controlled or a statement should be included in the method (6).

Pioglitazone hydrochloride $(\mathrm{PH})$ is 5-(4-[2-(5-ethylpyridin-2-yl)ethoxy] benzyl) thiazolidine-2,4-dione (Figure 1). It belongs to the BCS Class 2 and is practically insoluble in water but soluble in organic solvents like methanol, dimethyl sulfoxide, and dimethyl formamide. It selectively stimulates the nuclear peroxisome proliferator-activated gamma receptor (PPAR- $\gamma$ ) and, to a lesser extent, peroxisome proliferator-activated alpha receptor (PPAR- $\alpha$ ). It is primarily used in the treatment of diabetic conditions alone or in combination with other medications. It modulates the transcription of the insulin-sensitive genes involved in the control of glucose and lipid metabolism in the muscle, adipose tissue, and liver. As a result, it reduces insulin resistance in the liver and peripheral tissues, increases the expense of insulin-dependent glucose, decreases withdrawal of glucose from the liver, and reduces the quantity of glucose (7-9).

Although there is an increasing number of works describing the determination of $\mathrm{pH}$ in biological fluids and pharmaceutical formulations by several methods (10), this drug is not listed in any pharmacopoeia. The FDA has suggested experimental conditions for the dissolution test for PH tablets (11).

The aim of the present work was to establish experimental conditions for the dissolution test for pioglitazone in tablet dosage forms and to validate the dissolution test for specificity, precision, linearity and range, accuracy, and robustness.

\section{MATERIALS AND METHODS}

Pioglitazone hydrochloride reference standard (99.947\%) was kindly supplied by Aarti drugs Ltd, Mumbai. Piomed tablets (Batch No. DQO 003AK, manufacturing date: July 2010, expiry date: Dec 2013, IPCA Ltd, Pune) containing $15 \mathrm{mg}$ of pioglitazone hydrochloride were obtained commercially. Analytical reagent grade potassium chloride, potassium hydrogen phthalate, and hydrochloric acid (Qualigens, Mumbai); potassium hydrogen phosphate (Fischer Inorganics and Aromatics, Madras); and sodium hydroxide (Finar Ltd, Ahmadabad) were used. Freshly distilled water was used throughout

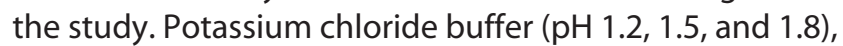
neutralized phthalate buffer $(\mathrm{pH} 4.4)$, mixed buffer $(\mathrm{pH}$ 6.8), phosphate buffer ( $\mathrm{pH} \mathrm{6.2,6.8,} \mathrm{and} \mathrm{7.2),} \mathrm{borate} \mathrm{buffer}$ (pH 8.0 and 8.6), and $0.1 \mathrm{~N} \mathrm{HCl}$ were prepared according to USP 27 (12).

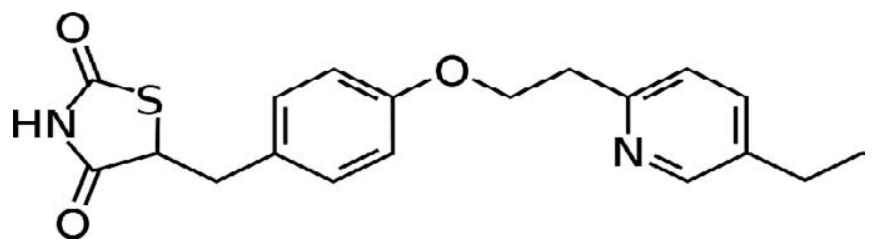

Figure 1. Chemical structure of pioglitazone hydrochloride.

\section{Apparatus}

The dissolution test was performed in a six-station Electrolab TDT dissolution tester (model TDT-06L) in accordance with USP 27 general methods. A Shimadzu UV-vis spectrophotometer (model UV-1800) using 1.0-cm quartz cells and Spectra Manager software were used for all absorbance measurements. A digital pH meter, model P101 (Hanna Instruments, Italy) was used to determine the $\mathrm{pH}$ of all solutions. The ultrasonic bath used for deaeration was the model U311 (Remi Equipments, Mumbai).

\section{Determination of Solubility and Sink Conditions}

Solubility data were used as the basis for the selection of a dissolution medium for pioglitazone hydrochloride. Drug solubility was determined at $25^{\circ} \mathrm{C}$ in different media and expressed as $\mathrm{mg} / \mathrm{mL}$. The term sink conditions (13) is defined as the volume of medium at least three times greater than that required to form a saturated solution of drug substance. Sink conditions were determined in different media: potassium chloride buffer ( $\mathrm{pH} \mathrm{1.2,} \mathrm{1.5,} \mathrm{and}$ 1.8), neutralized phthalate buffer ( $\mathrm{pH} 4.4)$, mixed buffer (pH 6.8), phosphate buffer ( $\mathrm{pH} 6.2,6.8$, and 7.2), borate buffer ( $\mathrm{pH} 8.0$ and 8.6), and $0.1 \mathrm{~N} \mathrm{HCl}$. Vessels $(n=3)$ containing $10 \mathrm{~mL}$ of medium and an excess of PH $(100 \mathrm{mg})$ were gently rotated on a mechanical shaker at a constant temperature $25^{\circ} \mathrm{C}$ for $24 \mathrm{~h}$ and then kept undisturbed for $4 \mathrm{~h}$ to attain equilibrium. The solution was filtered through Whatman No. 41 filter paper and analyzed spectrophotometrically at $269 \mathrm{~nm}$ after appropriate dilutions with $0.1 \mathrm{~N} \mathrm{HCl}$.

\section{Stability Determination}

Solution stability (1) was analyzed over $48 \mathrm{~h}$ at room temperature. Sample solutions were prepared in the same dissolution media and at the same conditions as for the dissolution test. Aliquots $(1 \mathrm{~mL})$ were collected initially and at 24-h intervals for 2 days and analyzed spectrophotometrically. The drug concentrations observed in samples at 0,24 , and $48 \mathrm{~h}$ were compared. The absolute differences between the results at time zero and the time of analysis indicate stability.

\section{Quality Control Testing of 15-mg Piomed Tablets}

Piomed tablets containing $15 \mathrm{mg}$ of pioglitazone hydrochloride were evaluated for color, shape, size, weight 
variation, friability, disintegration time, hardness, drug content, and content uniformity $(14,15)$.

\section{Mechanical Calibration of Dissolution Apparatus}

A recent FDA guideline (16) suggests that mechanical calibration can be used alternatively, and when properly executed, it can satisfy CGMP requirements. Conventionally, for oral solid dosage forms, dissolution Apparatus 1 or 2 is suggested. Hence, mechanical calibration was carried out for Apparatus 1 and 2.

\section{Optimization of Dissolution Test}

The dissolution experiments were conducted in a six-station bath dissolution apparatus by subjecting six Piomed tablets to $900 \mathrm{~mL}$ of each dissolution medium, both a paddle and a basket dissolution apparatus, and stirring speeds of 50,75 , and $100 \mathrm{rpm}(15,17,18)$. The temperature was stabilized at $37 \pm 0.5^{\circ} \mathrm{C}$. Aliquots of $10 \mathrm{~mL}$ were withdrawn manually at 5, 10, 15, 20, 30, and $40 \mathrm{~min}$. The same volume of medium at $37 \pm 0.5^{\circ} \mathrm{C}$ was replaced for constant volume. The sample was filtered through Whatman No. 41 filter paper and analyzed spectrophotometrically at $269 \mathrm{~nm}$. The standard solution used in all dissolution tests was prepared using pioglitazone equivalent to $15 \mathrm{mg}$. The UV spectrophotometric method was developed and validated in our laboratory.

\section{Filter Evaluation}

The filter evaluation is necessary to ensure that it does not adsorb drug and that it removes insoluble excipients that may otherwise cause high background or turbidity $(1,19)$. A standard and a sample solution were prepared in the proposed dissolution medium (potassium chloride buffer $\mathrm{pH}$ 1.5). The sample solutions were prepared using a placebo to which was added an amount of reference standard equivalent to $15 \mathrm{mg}$ of pioglitazone in a beaker with $900 \mathrm{~mL}$ dissolution medium at $37.0 \pm 0.5^{\circ} \mathrm{C}$ and stirred with a magnetic stirrer at $75 \mathrm{rpm}$ for $1 \mathrm{~h}$. Aliquots of $10 \mathrm{~mL}$ were withdrawn at the same point. The sample solutions were either centrifuged or filtered through Whatman No. 41 filter paper. The unfiltered solutions were treated as the standard solutions. They were diluted suitably, and all the solutions were analyzed spectrophotometrically. A filter is acceptable for use if the results of the filtered portions approach $98-102 \%$ of the original concentrations of the unfiltered standard solution and the centrifuged sample solution.

\section{Deaeration}

Deaerated medium is necessary for the evaluation of the dissolution behavior of drugs because nondeaerated medium causes variations in the amount of drug dissolved and an increase in the variability of the results $(19,20)$. A standard and sample solution of pioglitazone hydrochloride were prepared in the proposed dissolution medium, potassium chloride buffer $\mathrm{pH} 1.5$, at a final concentration of $20 \mu \mathrm{g} / \mathrm{mL}$. The sample solutions were prepared using $900 \mathrm{~mL}$ of nondeaerated medium. The medium was sonicated for $1 \mathrm{~h}$ at $37 \pm 0.5^{\circ} \mathrm{C}$. The standard solutions were prepared using $900 \mathrm{~mL}$ of the same medium after ultrasonication. All solutions were analyzed by the UV method. The results of the sample solutions were compared with those of the original concentrations of deaerated standard solutions.

\section{Validation of Dissolution Method}

The method was validated by the analysis of specificity, linearity, accuracy, precision, and robustness $(21,22)$ to demonstrate reproducibility and reliability.

\section{Specificity}

A placebo sample of the reference commercial formulation of tablets in the usual concentration of excipients was prepared to demonstrate reproducibility and reliability of the method. The placebo sample was transferred to vessels containing $900 \mathrm{~mL}$ of deaerated dissolution medium and stirred at $37^{\circ} \mathrm{C}$ for $1 \mathrm{~h}$ at $75 \mathrm{rpm}$ using a paddle apparatus. Aliquots of the solutions were filtered through Whatman No. 41 filter paper and analyzed by UV spectrophotometric method.

\section{Linearity}

Aliquots of pioglitazone hydrochloride stock solution $(100 \mu \mathrm{g} / \mathrm{mL})$ were diluted with $\mathrm{pH} 1.5$ potassium chloride buffer and $0.1 \mathrm{~N} \mathrm{HCl}$ to give concentrations of 10-60 $\mu \mathrm{g} /$ $\mathrm{mL}$. Each solution was prepared in triplicate. The linearity was evaluated by linear regression analysis, which was calculated by the least square regression method.

\section{Accuracy}

The recovery study was performed using a well-characterized lot of drug product with tight content uniformity. Pioglitazone hydrochloride reference substance was added to the dissolution vessels in known amounts at the $80 \%, 100 \%$, and $120 \%$ levels. Accordingly, 12, 15, and 18 $\mathrm{mg}$ of reference drug was added along with each 15-mg tablet. The dissolution test was performed on Piomed tablets for 40 min using $900 \mathrm{~mL}$ of $\mathrm{pH} 1.5$ potassium chloride buffer as medium in a paddle apparatus at $75 \mathrm{rpm}$. Aliquots of $10 \mathrm{~mL}$ were filtered through Whatman No. 41 filter paper and analyzed by UV spectrophotometric method at the spiked concentration levels of $80 \%, 100 \%$, and $120 \%$, respectively. Each concentration was analyzed in triplicate.

\section{Precision}

Repeatability (intraassay) was determined by analyzing six samples of Piomed tablets with the optimized dissolution test. Aliquots were collected and evaluated by the UV method at $269 \mathrm{~nm}$. Thus, repeatability was evaluated with the relative standard deviation (RSD) of the data at the $100 \%$ level. 
Table 1. Solubility of Pioglitazone Hydrochloride

\begin{tabular}{|c|c|c|c|c|}
\hline Buffer & pH & $\begin{array}{c}\text { Average Absorbance } \\
\text { mean } \pm \text { SD }(n=3)\end{array}$ & Concentration (mg/mL) & $C_{\mathrm{s}} / C_{\mathrm{d}}$ \\
\hline \multirow{3}{*}{ Potassium chloride } & 1.2 & $0.4317 \pm 0.125$ & 1.5026 & 9.036 \\
\hline & 1.5 & $0.3244 \pm 0.239$ & 1.1290 & 6.801 \\
\hline & 1.8 & $0.2821 \pm 0.589$ & 0.9819 & 5.909 \\
\hline Neutralized phthalate & 4.4 & $0.2593 \pm 0.248$ & 0.9021 & 5.433 \\
\hline \multirow{3}{*}{ Phosphate } & 6.2 & $0.0922 \pm 0.865$ & 0.3209 & 1.927 \\
\hline & 6.8 & $0.0336 \pm 0.795$ & 0.1169 & 0.698 \\
\hline & 7.2 & $0.0137 \pm 0.368$ & 0.0476 & 0.283 \\
\hline Mixed & 6.8 & $0.0012 \pm 0.657$ & 0.0041 & 0.024 \\
\hline $0.2 \mathrm{M}$ mixed & 6.8 & -0.0119 & - & - \\
\hline \multirow{2}{*}{ Borate } & 8.0 & $0.2923 \pm 0.458$ & 1.0160 & 6.351 \\
\hline & 8.6 & $0.1949 \pm 0.351$ & 0.6783 & 4.081 \\
\hline $0.1 \mathrm{~N}$ hydrochloric acid & 1.2 & $1.186 \pm 0.5481$ & 2.48 & 15.556 \\
\hline
\end{tabular}

The evaluation of intermediate precision was performed using a well-characterized lot of drug product of tight content uniformity. The intermediate precision (interday) was determined on different days by different analysts, and the RSD values were calculated. The dissolution test was performed on six Piomed tablets for 40 min using $900 \mathrm{~mL}$ of $\mathrm{pH} 1.5$ potassium chloride buffer as dissolution medium in Apparatus 2 at $75 \mathrm{rpm}$. Aliquots of $10 \mathrm{~mL}$ were filtered with quantitative filter and analyzed by the UV spectrophotometric method. Each concentration was analyzed in triplicate.

\section{Robustness}

The robustness was tested by changing several parameters of the dissolution method subsequently: analyst, equipment, and laboratory. The dissolution test was performed on six Piomed tablets for 40 min using $900 \mathrm{~mL}$ of $\mathrm{pH} 1.5$ potassium chloride buffer as medium in Apparatus 2 at 75 rpm in different laboratories, with two different analytical instruments in the same laboratory, and with two different analysts. Aliquots of $10 \mathrm{~mL}$ were filtered and analyzed by the UV method. The dissolution data were compared with the initial data.

\section{RESULTS AND DISCUSSION}

\section{Determination of Solubility and Sink Conditions}

The solubility profile of $\mathrm{PH}$ demonstrates that the solubility is $\mathrm{pH}$ dependent. PH exhibited substantial solubility at $\mathrm{pH} 1.2,1.5$, and 8.0 . The maximum solubility was observed in $0.1 \mathrm{~N} \mathrm{HCl}$. The solubility of $\mathrm{PH}$ increases as the $\mathrm{pH}$ decreases (Table 1) since $\mathrm{PH}$ is a weak base and exists in ionized form at a pH less than its $p K_{a}$ of 12.06 (18).

The solubility of $\mathrm{PH}$ in water was not tested because water is a nonideal dissolution medium for $\mathrm{PH}$. In addition, water quality is variable depending on the source and water $\mathrm{pH}$ is variable depending on the API and the excipients. Water is not considered a physiologically relevant medium as it is not representative of the gastric environment (23).

The ratio of saturation solubility to drug concentration (dose), expressed as $C_{s} / C_{d}$, represents the closeness to sink conditions; sink conditions occurs when the amount of drug that can be dissolved in the dissolution medium is three times greater than the amount of drug to be dissolved. A low $C_{s} / C_{d}$ ratio shows the existence of non-sink conditions. The rate of drug dissolution will be slowed by the limited solubility of the drug in that medium. In the present study, the value of $C_{s} / C_{d}$ is greater than 3 in potassium chloride buffer at $\mathrm{pH}$ 1.2, 1.5, and 1.8 (23); borate buffer at $\mathrm{pH} 8$; and $0.1 \mathrm{~N} \mathrm{HCl}$. Accordingly, sink conditions exist in a small volume of these dissolution media. A larger dissolution volume $(900 \mathrm{~mL})$ was selected considering the higher strength $\mathrm{PH}$ tablets (20).

\section{Stability Determination}

Drug solubility and solution stability are important properties to be considered when selecting the dissolution medium. If standard solutions are not stable in a dissolution medium for at least $24 \mathrm{~h}$ at ambient temperature, it should not be chosen (23). Stability study results (Table 2) reveal that the change in concentration of drug samples stored in different dissolution media (potassium chloride buffer $\mathrm{pH} 1.2,1.5$, and 1.8; borate buffer $\mathrm{pH}$ 8; and $0.1 \mathrm{~N}$ hydrochloric acid) and in light at $25^{\circ} \mathrm{C}$ over 2 days was less than $3 \%$ of that of reference solutions.

\section{Quality Control Testing of Piomed 15-mg Tablets}

Quality control test results of 15-mg Piomed tablets containing pioglitazone hydrochloride complied with IP specifications. (Results not reported.) 
Table 2. Stability Data for Pioglitazone Hydrochloride

\begin{tabular}{|c|c|c|c|c|c|c|}
\hline \multirow[b]{2}{*}{ Buffer } & \multirow[b]{2}{*}{ pH } & \multirow[b]{2}{*}{$0-\mathrm{h}$ conc. $(\mathrm{mg} / \mathrm{mL})$} & \multicolumn{2}{|c|}{$24 \mathrm{~h}$} & \multicolumn{2}{|c|}{$48 h$} \\
\hline & & & $\begin{array}{c}\text { conc. } \\
(\mathrm{mg} / \mathrm{mL})\end{array}$ & $\begin{array}{c}\% \text { difference with } \\
0-h(n=3)\end{array}$ & conc. $(\mathrm{mg} / \mathrm{mL})$ & $\begin{array}{c}\% \text { difference with } \\
0-h(n=3)\end{array}$ \\
\hline \multirow{3}{*}{ Potassium chloride } & 1.2 & 1.5026 & 1.4862 & 1.1 & 1.4689 & $2.243 \%$ \\
\hline & 1.5 & 1.1290 & 1.103 & 2.303 & 1.099 & 2.657 \\
\hline & 1.8 & 0.9819 & 0.991 & 0.92 & 0.9658 & 1.639 \\
\hline Neutralized phthalate & 4.4 & 0.9021 & 0.8543 & 5.298 & 0.8345 & 7.4936 \\
\hline \multirow{3}{*}{ Phosphate } & 6.2 & 0.3209 & 0.2968 & 7.51 & 0.2675 & 16.64 \\
\hline & 6.8 & 0.1169 & 0.1062 & 9.153 & 0.1045 & 10.607 \\
\hline & 7.2 & 0.0476 & 0.0456 & 4.20 & 0.0438 & 7.983 \\
\hline Mixed & 6.8 & 0.0041 & 0.0035 & 14.634 & 0.0038 & 7.317 \\
\hline $0.2 \mathrm{M}$ mixed & 6.8 & -0.0119 & - & - & - & - \\
\hline \multirow{2}{*}{ Borate } & 8.0 & 1.016 & 0.9964 & 1.929 & 0.9894 & 2.618 \\
\hline & 8.6 & 0.6783 & 0.6425 & 5.277 & 0.6398 & 5.675 \\
\hline $0.1 \mathrm{~N} \mathrm{HCl}$ & - & 2.485 & 2.43 & 2.016 & 2.41 & 2.822 \\
\hline
\end{tabular}

\section{Mechanical Calibration of Dissolution Apparatus}

The results of the mechanical calibration demonstrated the suitability of the dissolution apparatus for test purposes. (Results not reported.)

\section{Optimization of Dissolution Test}

Correlation of the solubility and stability data and the influence of sink conditions indicate that potassium chloride buffer $\mathrm{pH} 1.2,1.5$, and 1.8; borate buffer $\mathrm{pH}$ 8 ; and $0.1 \mathrm{~N}$ hydrochloric acid are suitable dissolution media. The results of the dissolution study are depicted in Figures 2-5.

The results indicate that dissolution of $\mathrm{PH}$ from Piomed tablets was $\mathrm{pH}$ dependent. In the case of potassium chloride buffer $\mathrm{pH} 1.2$, the amount dissolved was less as compared with potassium chloride buffer $\mathrm{pH} 1.5$, probably due to a decrease in the surface ionization at pH 1.2. The dissolution was reduced with an increase in the $\mathrm{pH}$

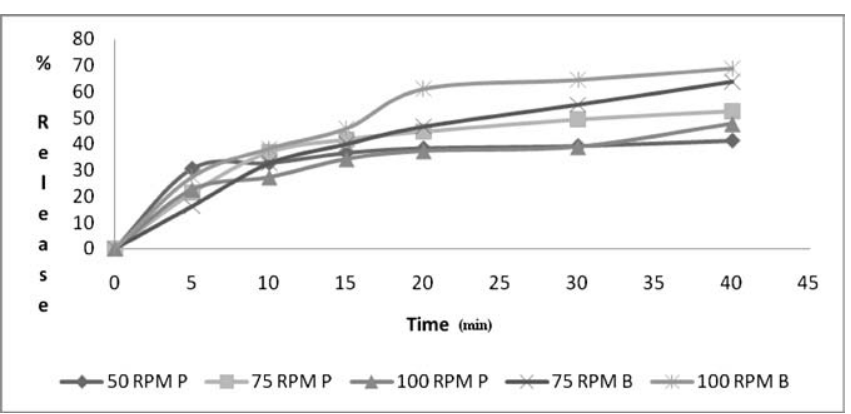

Figure 2. Dissolution profiles of Piomed tablets in $\mathrm{pH} 1.2$ potassium chloride buffer. of the dissolution medium from 1.5 to 1.8 . These observations corroborate the findings of Sayer et al. (24), who reported that dissolution of both trimethoprim and sulfamethoxazole from co-trimoxazole tablets was $\mathrm{pH}$ dependent. The dissolution guidelines recommend that the $\mathrm{pH}$ of the dissolution medium should not exceed 8. Therefore, borate buffer $\mathrm{pH} 8$ was not considered while optimizing the dissolution method (13).

Dissolution of drug from a dosage form involves at least two consecutive steps, liberation of the drug from the formulation matrix (disintegration) followed by dissolution of the drug (solubilization of the drug particles) in the dissolution medium. For most of the immediate-release formulations of poorly soluble drugs, the rate of dissolution is intrinsically controlled. Although the solubility of $\mathrm{PH}$ was greater in potassium chloride buffer $\mathrm{pH} 1.2$ than in potassium chloride buffer $\mathrm{pH} 1.5$, the amount of $\mathrm{PH}$ dissolved in the $\mathrm{pH} 1.2$ buffer was less than in the $\mathrm{pH} 1.5$

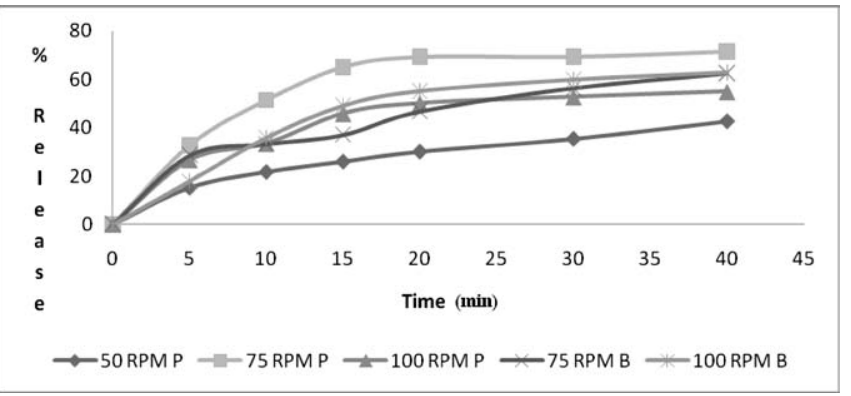

Figure 3. Dissolution profiles of Piomed tablets in $\mathrm{pH} 1.5$ potassium chloride buffer. 


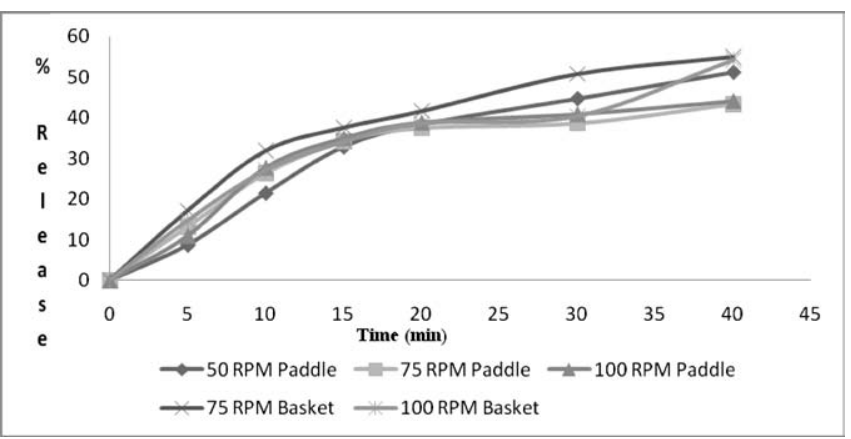

Figure 4. Dissolution profiles of Piomed tablets in $\mathrm{pH} 1.8$ potassium chloride buffer.

buffer. This may be due to a lower rate of intrinsic dissolution of $\mathrm{PH}$ in potassium chloride buffer $\mathrm{pH}$ 1.2. The rate of precipitation ( $K_{\text {precipitation}}$ ) of $\mathrm{PH}$ may be slightly more than the rate of disintegration $\left(K_{\text {disintegration }}\right)$ in potassium chloride buffer $\mathrm{pH} 1.2$ (25).

The dissolution profiles demonstrate incomplete dissolution of $\mathrm{PH}$ tablets in potassium chloride buffer $\mathrm{pH}$ 1.2, 1.5 , and 1.8 , in paddle or basket apparatus, at the stirring speeds of 50,75, and $100 \mathrm{rpm}$. The percent release was less than $85 \%$ within $30 \mathrm{~min}$; therefore, the minimum requirements established by USFDA were not satisfied (26). On the other hand, the use of $0.1 \mathrm{~N}$ hydrochloric acid dissolution medium with a paddle or basket apparatus at 50,75 , and $100 \mathrm{rpm}$ yielded a satisfactory dissolution of the drug in the first $30 \mathrm{~min}$ of the test, with drug release greater than $85 \%$. The FDA guideline for dissolution testing of immediate-release solid oral dosage forms (26) recommends a two-point dissolution specification for slowly dissolving or poorly water soluble drugs (BCS Class 2), one at $15 \mathrm{~min}$ to include a dissolution range (a dissolution window) and the other at a later point $(30,45$, or $60 \mathrm{~min})$ to ensure $85 \%$ dissolution. The dissolution test conditions suggested by FDA for pioglitazone hydrochloride tablets

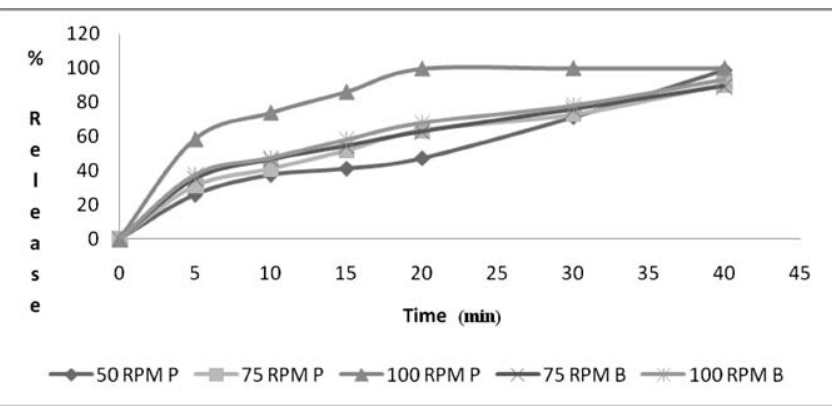

Figure 5. Dissolution profiles of Piomed tablets in $0.1 \mathrm{~N}$ hydrochloric acid.

(11), namely a collection time of $30 \mathrm{~min}$, are inadequate, and more samples are essential.

Drug release was greater with the paddle apparatus. The selection of the stirring speed was based on the recommended range for Apparatus 1 and 2 for tablets. The effect of rotation speed of the paddles on the dissolution profile of $\mathrm{PH}$ was examined at 50,75, and $100 \mathrm{rpm}$. In general, mild agitation conditions and less volume of dissolution medium should be maintained during dissolution testing to allow maximum discriminatory power since the dissolution apparatus tends to become less discriminating when operated at faster speeds, resulting in a flatter drug release profile (26).

When $0.1 \mathrm{~N}$ hydrochloric acid was used as the dissolution medium, $\mathrm{PH}$ showed a faster dissolution rate, which was not desirable because this condition may not reflect in vivo performance and an adequate capacity to differentiate between different formulations. The dissolution profile obtained in potassium chloride buffer $\mathrm{pH} 1.5$ for paddle apparatus at $75 \mathrm{rpm}$ was slower and may have better capacity to differentiate the formulations. One of the desirable features of the dissolution method is its discriminatory capacity (27). In potassium chloride buffer

Table 3. Dissolution Release Rate of Piomed Tablets in pH 1.5 Potassium Chloride Buffer, Paddle Apparatus, 75 rpm

\begin{tabular}{|c|c|c|c|c|c|c|c|c|}
\hline \multirow[b]{2}{*}{ Sr. No. } & \multirow[b]{2}{*}{ Time (min) } & \multicolumn{6}{|c|}{$\%$ Release } & \multirow[b]{2}{*}{ Avg \% Release } \\
\hline & & 1 & 2 & 3 & 4 & 5 & 6 & \\
\hline 1 & 0 & 0.017 & 0.022 & 0.029 & 0.025 & 0.037 & 0.041 & 0.028 \\
\hline 2 & 5 & 34.586 & 32.956 & 32.142 & 33.799 & 34.485 & 30.244 & 33.035 \\
\hline 3 & 10 & 46.470 & 44.469 & 50.699 & 54.474 & 53.139 & 51.764 & 50.169 \\
\hline 4 & 15 & 64.764 & 65.481 & 64.191 & 67.253 & 65.477 & 65.532 & 65.449 \\
\hline 5 & 20 & 68.351 & 68.112 & 69.834 & 69.774 & 68.115 & 68.789 & 68.829 \\
\hline 6 & 30 & 73.584 & 73.982 & 72.951 & 70.574 & 73.998 & 72.899 & 73.987 \\
\hline 7 & 40 & 76.798 & 75.315 & 75.015 & 74.544 & 76.712 & 74.764 & 75.858 \\
\hline 8 & 50 & 80.489 & 79.459 & 81.889 & 81.995 & 82.112 & 81.792 & 80.789 \\
\hline 9 & 60 & 85.248 & 86.149 & 85.148 & 86.479 & 84.169 & 87.994 & 85.864 \\
\hline 10 & 70 & 91.154 & 90.668 & 90.024 & 91.791 & 90.498 & 92.358 & 91.082 \\
\hline
\end{tabular}


Table 4. Dissolution Test Linearity Results for Pioglitazone Hydrochloride

\begin{tabular}{ccc}
\hline Sr. No. & $\begin{array}{c}\text { Concentration } \\
(\mu \mathrm{g} / \mathrm{mL})\end{array}$ & $\begin{array}{c}\text { Absorbance } \pm \text { Standard Deviation } \\
(n=3)\end{array}$ \\
\hline 1 & 10 & $0.2380 \pm 0.003551$ \\
\hline 2 & 20 & $0.4620 \pm 0.003404$ \\
\hline 3 & 30 & $0.7028 \pm 0.003593$ \\
\hline 4 & 40 & $0.9034 \pm 0.002524$ \\
\hline 5 & 50 & $1.1134 \pm 0.000917$ \\
\hline 6 & 60 & $1.3600 \pm 0.001000$ \\
\hline
\end{tabular}

$\mathrm{pH} 1.5$, drug release was slower than in $0.1 \mathrm{~N}$ hydrochloric acid. For the same reason, Mendonca et al. (28) selected phosphate buffer $\mathrm{pH} 6.8$ instead of $0.1 \mathrm{M}$ hydrochloric acid to study the release rate of dilitazime hydrochloride. Vaucher et al. (1) chose phosphate buffer $\mathrm{pH} 7.5$ for the dissolution method for coated telithromycin tablets. The optimum dissolution conditions for the assessment of $\mathrm{PH}$ release rate were $900 \mathrm{~mL}$ of potassium chloride buffer $\mathrm{pH}$ 1.5 at $37^{\circ} \mathrm{C}$ as the dissolution medium, paddle apparatus at a stirring speed of $75 \mathrm{rpm}$ and $60 \mathrm{~min}$ as collection time (Table 3).

\section{Filter Evaluation}

The results of the filter evaluation reveal that the absolute differences between the concentrations of standard samples (in potassium chloride buffer $\mathrm{pH} 1.5$ ) and filtered/ centrifuged samples were within $98-102 \%$. This demonstrates the absence of $\mathrm{PH}$ adsorption by the filter and the suitability of Whatman No. 41 filter paper in the dissolution test (1).

\section{Deaeration}

The effect of dissolved gases in the medium on $\mathrm{PH}$ dissolution revealed that the amount of dissolved drug was less in nondeaerated medium and the results were more variable $(1,20)$. Thus, deaerated dissolution media was needed during dissolution study.

\section{Validation of Dissolution Test}

After the best experimental conditions were selected, the dissolution test was validated (17-22).

\section{Specificity}

When the placebo tablets were subjected to the dissolution test and analyzed, the corresponding absorbance was equivalent to $1.64 \% \mathrm{PH}$ concentration. According to $\mathrm{ICH}$ guidelines, the dissolution method is specific if the

Table 5. Dissolution Test Accuracy Results for Pioglitazone Hydrochloride

\begin{tabular}{clccc}
\hline Sr. No. & \multicolumn{1}{c}{ Parameter } & \multicolumn{2}{c}{ Levels } \\
\hline 1 & Tablet amount $(\mathrm{mg})$ & 15 & 15 & 15 \\
\hline 2 & Level of addition $(\%)$ & 80 & 100 & 120 \\
\hline 3 & Amount added $(\mathrm{mg})$ & 12 & 15 & 18 \\
\hline 4 & Average amount recovered $(\mathrm{mg})$ & 26.03 & 30.072 & 32.396 \\
\hline 5 & Average $\%$ recovery & \\
\hline${ }^{a}$ Each reading is mean $\pm S D(n=3)$ & $96.407 \pm 2.1432$ & $100.24 \pm 2.5041$ & $98.17 \pm 2.189$ \\
\hline
\end{tabular}

Table 6. Dissolution Test Precision (Intraday) Results for Pioglitazone Hydrochloride

\begin{tabular}{|c|c|c|c|c|}
\hline \multirow[b]{2}{*}{ Sr. No. } & \multirow[b]{2}{*}{ Time (min) } & \multicolumn{3}{|c|}{ Average $\%$ Release \pm SD $(n=3)$} \\
\hline & & $10: 00 \mathrm{am}$ & $3: 00$ pm & $8: 00$ pm \\
\hline 1 & 0 & $0.021 \pm 0.8754$ & $0.030 \pm 1.1487$ & $0.028 \pm 1.5479$ \\
\hline 2 & 5 & $30.879 \pm 0.5945$ & $33.258 \pm 0.8862$ & $34.298 \pm 0.4873$ \\
\hline 3 & 10 & $50.569 \pm 1.1580$ & $54.897 \pm 1.7542$ & $52.487 \pm 0.8769$ \\
\hline 4 & 15 & $64.848 \pm 1.1173$ & $66.557 \pm 1.2350$ & $67.589 \pm 1.5731$ \\
\hline 5 & 20 & $66.598 \pm 0.4861$ & $67.883 \pm 1.0263$ & $68.359 \pm 1.2287$ \\
\hline 6 & 30 & $69.667 \pm 0.8975$ & $70.487 \pm 0.3892$ & $71.028 \pm 0.8534$ \\
\hline 7 & 40 & $72.589 \pm 0.7756$ & $73.589 \pm 1.4875$ & $73.669 \pm 0.7724$ \\
\hline 8 & Average at $40 \mathrm{~min}$ & $73.282 \pm 1.0118$ & & \\
\hline 9 & $\% \mathrm{RSD}$ at $40 \mathrm{~min}$ & 1.704 & & \\
\hline
\end{tabular}


Table 7. Dissolution Test Precision (Interday) Results for Pioglitazone Hydrochloride

\begin{tabular}{|c|c|c|c|c|}
\hline \multirow[b]{2}{*}{ Sr. No. } & \multirow[b]{2}{*}{ Time (min) } & \multicolumn{3}{|c|}{ Average $\%$ Release \pm SD $(n=3)$} \\
\hline & & Day I & Day II & Day III \\
\hline 1 & 0 & $0.024 \pm 0.9857$ & $0.047 \pm 1.154$ & $0.035 \pm 0.8754$ \\
\hline 2 & 5 & $34.215 \pm 0.8976$ & $35.996 \pm 0.5825$ & $37.548 \pm 0.7450$ \\
\hline 3 & 10 & $53.587 \pm 1.0258$ & $51.287 \pm 0.9786$ & $50.897 \pm 0.4897$ \\
\hline 4 & 15 & $66.879 \pm 0.4598$ & $64.897 \pm 1.1258$ & $65.248 \pm 0.8769$ \\
\hline 5 & 20 & $68.259 \pm 0.9941$ & $67.258 \pm 0.6987$ & $68.573 \pm 0.9581$ \\
\hline 6 & 30 & $70.168 \pm 1.1160$ & $69.588 \pm 1.5870$ & $69.557 \pm 0.5974$ \\
\hline 7 & 40 & $72.975 \pm 0.4126$ & $71.665 \pm 0.3598$ & $73.215 \pm 0.2587$ \\
\hline 8 & Average at $40 \mathrm{~min}$ & $72.618 \pm 1.0072$ & & \\
\hline 9 & $\%$ RSD at $40 \mathrm{~min}$ & 1.3869 & & \\
\hline
\end{tabular}

Table 8. Robustness of Dissolution Test with Change in Analyst

\begin{tabular}{cccc}
\hline & & \multicolumn{2}{c}{ Average $\%$ Release \pm SD $(\boldsymbol{n}=\mathbf{3})$} \\
\cline { 2 - 4 } Sr. No. & Time $(\mathbf{m i n})$ & Analyst I & Analyst II \\
\hline 1 & 0 & $0.021 \pm 1.1453$ & $0.034 \pm 0.9754$ \\
\hline 2 & 5 & $33.328 \pm 0.7658$ & $34.056 \pm 0.4581$ \\
\hline 3 & 10 & $50.269 \pm 1.125$ & $49.568 \pm 1.1487$ \\
\hline 4 & 15 & $63.548 \pm 0.8815$ & $64.115 \pm 1.4598$ \\
\hline 6 & 20 & $66.287 \pm 1.548$ & $68.149 \pm 0.8736$ \\
\hline 7 & 30 & $69.581 \pm 0.9568$ & $70.298 \pm 1.558$ \\
\hline 8 & 40 & $71.695 \pm 1.056$ & $73.258 \pm 0.7598$ \\
\hline 9 & Average at $40 \mathrm{~min}$ & $72.476 \pm 1.0483$ & 1.446 \\
\hline
\end{tabular}

interference is not more than $2 \%$. The dissolution method was specific.

\section{Linearity}

To assess linearity, a standard curve for $\mathrm{PH}$ was constructed by plotting average absorbance versus concentration (Table 4). The curves depict good linearity in the range of $10-60 \mu \mathrm{g} / \mathrm{mL}$. The line equation was $y=0.0286 x$ +0.0007 with a slope of 0.0286 and $r^{2}$ of 0.999 . The RSD for each point was less than $2 \%$. These data indicate that the method is linear for pioglitazone within the specification limits.

\section{Accuracy}

The accuracy expresses the agreement between the accepted value and the observed value. According to $\mathrm{ICH}$ guidelines, the recovery for a dissolution test must be in the range of $95-105 \%$. The percent recovery was from $96.407 \%$ to $100.24 \%$. The accuracy of the method is acceptable (Table 5).

\section{Precision}

The percent RSD did not exceed $5 \%$ for the repeatability and intermediate precision, demonstrating suitable precision (Tables 6 and 7).

\section{Robustness}

The robustness of the method was demonstrated by changing the analyst, the instrument, and the laboratory (interlaboratory study). The percent RSD values were within the specified limit of $5 \%$ indicating the robustness of dissolution method (Tables 8-10).

\section{CONCLUSION}

The dissolution test developed and validated for pioglitazone tablets is considered satisfactory. The most discriminating conditions for dissolution testing of pioglitazone tablets (i.e., pH 1.5 potassium chloride buffer medium, paddle apparatus, stirring speed of $75 \mathrm{rpm}$, and collection time of $60 \mathrm{~min}$ ) appear to be the best condition. The validation shows that the dissolution test is appropri- 
Table 9. Robustness of Dissolution Test with Change in Equipment

\begin{tabular}{cccc}
\hline & & \multicolumn{2}{c}{ Average \% Release \pm SD $(\boldsymbol{n}=\mathbf{3})$} \\
\cline { 3 - 4 } Sr. No. & Time $(\boldsymbol{m i n})$ & Equipment I & Equipment II \\
\hline 1 & 0 & $0.019 \pm 0.8756$ & $0.024 \pm 1.5473$ \\
\hline 2 & 5 & $32.215 \pm 0.9856$ & $35.568 \pm 1.1140$ \\
\hline 3 & 10 & $48.569 \pm 0.8567$ & $50.369 \pm 1.2587$ \\
\hline 4 & 15 & $61.458 \pm 1.0594$ & $63.285 \pm 1.5871$ \\
\hline 5 & 20 & $65.187 \pm 0.6579$ & $66.874 \pm 1.2897$ \\
\hline 6 & 30 & $68.125 \pm 1.1465$ & $70.459 \pm 1.4875$ \\
\hline 7 & 40 & $71.548 \pm 0.9954$ & $72.759 \pm 1.1458$ \\
\hline 8 & Average at 40 $\mathrm{min}$ & $72.153 \pm 1.0706$ & \\
\hline 9 & $\%$ RSD at $40 \mathrm{~min}$ & 1.484 &
\end{tabular}

Table 10. Robustness of Dissolution Test with Change in Laboratory

\begin{tabular}{cccc}
\hline & & \multicolumn{2}{c}{ Average \% Release \pm SD $(\boldsymbol{n}=\mathbf{3})$} \\
\cline { 3 - 4 } Sr. No. & Time $(\boldsymbol{m i n})$ & Laboratory I & Laboratory II \\
\hline 1 & 0 & $0.024 \pm 1.2487$ & $0.037 \pm 0.5476$ \\
\hline 2 & 5 & $33.154 \pm 1.2481$ & $34.158 \pm 0.5874$ \\
\hline 3 & 10 & $46.879 \pm 1.1254$ & $48.247 \pm 1.485$ \\
\hline 4 & 15 & $60.887 \pm 0.9570$ & $62.587 \pm 0.8576$ \\
\hline 5 & 20 & $64.589 \pm 1.5486$ & $65.218 \pm 0.9758$ \\
\hline 6 & 30 & $67.256 \pm 0.8659$ & $69.115 \pm 1.5874$ \\
\hline 7 & 40 & $70.556 \pm 1.3598$ & $72.876 \pm 0.7798$ \\
\hline 8 & Average at 40 $\mathrm{min}$ & $71.692 \pm 1.0698$ & \\
\hline 9 & $\%$ RSD at 40 $\mathrm{min}$ & 1.492 & \\
\hline
\end{tabular}

ate for quantification of pioglitazone in tablet pharmaceutical form for in vitro studies, presenting selectivity, linearity, precision, accuracy, and robustness. The method is adequate for use in quality control testing of pioglitazone tablets since a dissolution test is not indicated in an official monograph, but is included in Pharmacopeial Forum.

\section{ACKNOWLEDGMENTS}

The authors are grateful to Padmashree Mrs. Fatma Rafiq Zakaria for encouraging and providing the research facilities. The authors are thankful to Aarti Drugs Limited, Mumbai, for providing the gift sample of pioglitazone hydrochloride.

\section{REFERENCES}

1. Vaucher, L. C. Development and validation of a dissolution test for telithromycin in coated tablets. Quim. Nova 2009, 32 (5), 1-5.

2. Oliveira, E.; Azevedo, R.; Bonfilio, R.; Oliveira, D. B.; Ribeiro, G. P.; Araujo, M. B.. Dissolution test optimization for meloxicam in the tablet pharmaceutical form. Braz. J. Pharm. Sci. 2009, 45 (1), 67-73.
3. Soni, T.; Nagda, C.; Gandhi, T.; Chotai, N. P.

Development of discriminating method for dissolution of aceclofenac marketed formulations. Dissolution Technol. 2008, 15 (2), 31-35.

4. Dressman, J. B.; Amidon, G. L.; Reppas, C.; Shah, V. P. Dissolution Testing as a Prognostic Tool for Oral Drug Absorption: Immediate Release Dosage Forms. Pharm. Res. 1998, 15 (1), 11-22.

5. Ansari, M.; Kazemipour, M.; Talebnia, J. The Development and Validation of a Dissolution Method for Chlomipramine Solid Dosage Forms. Dissolution Technol. 2004, 11 (3), 16-24.

6. Space, J. S.; Opio, A. M.; Nickerson, B.; Giang, H.; Dumont, M.; Berry, M. Validation of a dissolution method with HPLC analysis for lasofoxifene tartrate low dose tablets. J. Pharm. Biomed. Anal. 2007, 44 (5), 1064-1071.

7. Pioglitazone product information. Cayman Chemical Company Web site. https://www.caymanchem.com/ app/template/Product.vm/catalog/71745 (accessed Oct 9, 2012). 
8. ACTOS (pioglitazone hydrochloride) Tablets. RxList: The Internet Drug Index Web site. http://www.rxlist. com/actos-drug.htm (accessed Oct 9, 2012).

9. Pioglitazone; MSDS No. 71745 [Online]; Cayman Chemical Company: Ann Arbor, MI, May 3, 2006. http:// www.caymanchem.com/msdss/71745m.pdf (accessed Oct 9, 2012).

10. Alim, M. A Study of Pioglitazone Biokinetics, Renal Clearance and Its Effects on Glycation Level. Ph.D. Dissertation, University of Agriculture, Faisalabad, Pakistan, 2009.

11. U.S. Food and Drug Administration. Dissolution Methods Database Web site. http://www.accessdata. fda.gov/scripts/cder/dissolution/index.cfm (accessed Oct 20, 2012).

12. The United States Pharmacopeia and National Formulary USP 27-NF 24; The United States Pharmacopeial Convention, Inc.: Rockville, MD, 2007.

13. Garcia, C. V.; Paim, C. S.; Steppe, M.; Schapoval, E. E.S. Development and validation of a dissolution test for rabeprazole sodium in coated tablets. J. Pharm. Biomed. Anal. 2006, 41 (3), 833-837.

14. Indian Pharmacopoeia. Ministry of Health and Family Welfare, Indian Pharmacopoeia Commission: Ghaziabad, India, 2007; pp 179-182.

15. Patel, P. A.; Patravale, V. B. Commercial Telmisartan Tablets: A Comparative Evaluation with Innovator Brand Micardis. Int. J. Pharm. Sci. Res. 2010, 1 (8), 282-292.

16. The Use of Mechanical Calibration of Dissolution Apparatus 1 and 2-Current Good Manufacturing Practice (CGMP); Guidance for Industry; U.S. Department of Health and Human Services, Food and Drug Administration, Center for Drug Evaluation and Research (CDER), U.S. Government Printing Office: Washington, DC, 2010.

17. Breier, A. R.; Paim, C. S.; Steppe, M.; Schapoval, E. E. S. Development and validation of dissolution tests for fexofenadine hydrochloride capsules and coated tablets. J. Pharm. Pharm. Sci. 2005, 8 (2), 289-298.

18. Shohin, I. E.; Kulinich, J. I.; Ramensakya, G. V.; Vasilenko, G. F. Evaluation of In Vitro Equivalence for Drugs
Containing BCS Class II Compound Ketoprofen. Dissolution Technol. 2011, 18 (1), 26-29.

19. Swartz, M.; Emanuele, M. Developing and Validating Dissolution Procedures for Improved Product Quality, 2009. White Paper. Smithers Pharma Services Web site. http://www.smitherspharma.com/resources (accessed Oct 10, 2012).

20. Sperandeo, N. R.; Kassuha, D. E. Development and Validation of a Dissolution Test for $6 \mathrm{mg}$ Deflazacort Tablets. Sci. Pharm. 2009, 77, 679-693.

21. International Conference on Harmonisation. Validation of Analytical Procedures: Text and Methodology, Q2(R1);ICH Harmonized Tripartite Guideline: Geneva, Switzerland, 2005.

22. The United States Pharmacopeia and National Formulary USP 32-NF 27; The United States Pharmacopeial Convention, Inc.: Rockville, MD, 2009.

23. Gowthamarajan, K.; Singh, S. K. Dissolution Testing for Poorly Soluble Drugs: A Continuing Perspective. Dissolution Technol. 2010, 17 (3), 24-32.

24. Sayar, E.; Şahin, S.; Cevheroğlu, Ş.; Hinchal, A. A. Comparison of Dissolution Profiles of Two Commercially Available Co-Trimoxazole Tablets. FABAD J. Pharm. Sci. 2008, 33, 87-94.

25. Brown, C. K.; Chokshi, H. P.; Nickerson, B.; Reed, R. A.; Rohrs, B. R.; Shah, P. A. Acceptable Analytical Practices for Dissolution Testing of Poorly Soluble Compounds. Pharm. Tech. 2004, 28 (12), 56-65.

26. Dissolution Testing of Immediate Release Solid Oral Dosage Forms; Guidance for Industry; U.S. Department of Health and Human Services, Food and Drug Administration, Center for Drug Evaluation and Research (CDER), U.S. Government Printing Office: Washington, DC, 1997.

27. Qureshi, S. A. Developing Discriminatory Drug Dissolution Tests and Profiles: Some Thoughts for Consideration on the Concept and Its Interpretation. Dissolution Technol. 2006, 13 (4), 18-23.

28. Mendonça, T. F.; de Barros, E. G.; Pereira, G. R.; de Araújo, M. B.; Bonfilio, R. Development and validation of dissolution test for diltiazem hydrochloride in immediate release capsules. Quim. Nova. 2011, 34 (3), 1-7. 